\title{
Learning Analytics for Primary and Secondary Schools
}

\author{
Vitomir Kovanovic ${ }^{1}$, Claudia Mazziotti ${ }^{2}$, Jason Lodge ${ }^{3}$
}

\begin{abstract}
Over the past decade, the increasing use of learning analytics opened the possibility of making data-driven decisions for improving student learning. Driven by the strong university adoption of learning analytics, most early learning analytics research focused on issues specific to tertiary education. With the broader adoption of educational technologies in primary and secondary education and the emergence of new classroom-focused technologies, there has been a growing awareness of the potentials of learning analytics for supporting students and diagnosing their learning progress in pre-university contexts. This special section focused on investigating, developing, and evaluating state-of-the-art learning analytics approaches within primary and secondary school settings. In this editorial, we summarize the papers of the special section and discuss the challenges and opportunities for learning analytics within the school context. We conclude with the discussion around the opportunities for future work and the implications of this special section for the field of learning analytics.
\end{abstract}

\section{Keywords}

Primary schools, secondary schools, learning analytics adoption

Submitted: 12/07/21 — Accepted: 12/07/21 — Published: 03/09/21

Corresponding author ${ }^{1}$ Email: vitomir.kovanovic@unisa.edu.au Address: Centre for Change and Complexity in Learning, University of South Australia, City West Campus BH3-21, Adelaide, SA 5000, Australia. ORCID ID: https://orcid.org/0000-0001-9694-6033

2Email: claudia.mazziotti@rub.de Address: TUM School of Education, Technical University Munich, Marsstraße 20-22, 80335 Munich, Germany.

${ }^{3}$ Email: jason.lodge@uq.edu.au Address: School of Education, Faculty of Humanities and Social Sciences, The University of Queensland, Brisbane, Australia, ORCID ID: https://orcid.org/0000-0001-6330-6160

\section{Introduction}

Over the past decade, there has been substantial growth in the adoption of learning analytics and data-driven techniques for improving teaching and learning. Learning analytics have made possible data-driven decisions for improving student learning, utilizing the data already collected by educational tools and platforms. However, focusing on online and blended learning and issues such as student retention, at-risk prediction, and study approaches, most of the previous work has focused on tertiary education and specific issues for that context (Li et al., 2015; Sancho et al., 2015). With the broader adoption of educational technologies in primary and secondary education and the emergence of new classroom-focused technologies (Horn \& Staker, 2011; Voogt et al., 2018), there has been a growing awareness of the potentials of learning analytics for supporting students and diagnosing their learning progress in pre-university contexts.

While the adoption of analytics has drawn sharp criticism (McRae, 2014; Roberts-Mahoney et al., 2016; Selwyn \& Facer, 2013), there is also a growing realization of the unique opportunities that analytics provide in supporting contemporary teaching and learning. The 2017 Horizon $\mathrm{K}-12$ report estimated 2-3 years as the time to broader adoption of learning analytics within primary and secondary domains, with main opportunities being to "predict learner outcomes, trigger interventions or curricular adaptations, and even prescribe new pathways or strategies to improve student success" (Freeman et al., 2017, p. 44). Similar benefits and opportunities were noted by the earlier US Department of Education report (Bienkowski et al., 2012) and the more recent Australian Gonski et al. (2018) report, which emphasize the power of data and analytics to provide more personalized learning experiences and improve student learning outcomes. Moreover, there have been substantial developments within the learning analytics field itself: The development of multimodal learning analytics (MMLA; Ochoa, 2017) as well as novel classroom-based analytics systems (Lodge et al., 2018) provide analytical approaches far more suitable for primary and secondary school contexts. Since 2018, a full-day pre-conference event on learning analytics adoption within schools has been running at the LAK conference, witnessing strong interest by schoolteachers, administrators, policymakers, and industry representatives. 
There are two key reasons why this special section is timely and needed. The maturity of learning analytics means that the lessons learned from the higher education context can be applied with care to students' learning in contexts where ethics and privacy issues are arguably more critical and complicated (Gunawardena, 2017; Singer, 2014). Most notably, however, there has been a marked shift in the use of digital technologies in primary and secondary school settings due to the social distancing and online learning requirements mandated by the COVID-19 pandemic. Digital learning environments in these educational settings were already on the rise but the pandemic seems to have accelerated their use. Understanding how to maximize the utility of learning analytics in these contexts in an ethical and inclusive way is, therefore, an urgent need. As is the case with higher education, in addition to the challenges of ethical use of learning analytics in primary and secondary schools, there are opportunities for greatly enhancing our collective understanding of how students learn in these contexts and what kinds of activities and practices have the greatest impact on student development.

\section{Summary of Special Section}

This special section consists of five research articles and one practitioner report paper. The papers encompass a wide range of methods and approaches for addressing a broad range of issues, from understanding teacher perceptions of learning analytics dashboards to data sharing and interoperability standards.

The first paper by van Leeuwen et al. (2021) examines how teacher characteristics affect their use of learning analytics dashboards. Using the data from two case studies, the authors show that — while the use of LA dashboards varied dramatically - the demographic characteristics of teachers (e.g., age, gender) were not significantly associated with their use of learning analytics dashboards, challenging some of the preconceptions around the negative influence of certain demographic factors towards adoption of learning analytics. To support better teacher professional development around LA dashboard use, van Leeuwen et al. (2021) outline an integrated model for teacher dashboard use, showing key factors that affect the use of teacher-facing dashboards in the school context.

The importance of aligning learning analytics and learning design has been explored by the second paper by RodríguezTriana et al. (2021), who evaluate alignment of (learning) analytics and design (ADA) within the context of inquiry-based learning (IBL). Looking at how instructors use a whole range of orchestration tools, Rodríguez-Triana et al. (2021) identified a set of design needs to effectively support the orchestration of IBL. Such recommendations can significantly impact how orchestration tools are developed and implemented in practice, pushing forward the adoption of IBL educational technologies within school classrooms.

While helping students in their learning tasks and activities is important, it is equally important to support them to reflect on their actions and help them observe and inspect their thoughts and actions. The third paper by Cloude et al. (2021) examines the self-reflection support of secondary school students within a game-based learning environment. Using self-reflection prompts, the authors examined the characteristics of student self-reflection and how these relate to the successful completion of game learning tasks and goals. Cloude et al. (2021) found that depth and quality of reflection — rather than quantity - was associated with successful problem-solving. Such findings, combined with practical insights for building effective reflection prompts, provide an important foundation for understanding student problem solving and supporting teachers in the classrooms.

Looking at ways to integrate different student data, the fourth paper by Krumm et al. (2021) explores the integration and data sharing between different educational technologies. Evaluating the integration of vastly different software tools for teaching grade 3-4 mathematics, Krumm et al. (2021) show that integration is not so much a technical but a semantic interoperability challenge that is highly context dependent. The findings show the importance of non-technical activities for supporting data integration and sharing as well as the importance of understanding different domains and learning contexts.

While data sharing is highly important and provides significant benefits, the fifth paper by Yacobson et al. (2021) reminds us that data sharing comes with significant data privacy challenges. In their study, Yacobson et al. (2021) demonstrated how de-identified data about mathematics learning by fifth-grade students could be successfully re-identified using information publicly available on their schools' websites. By linking the irregularities in student behaviour (surprising gaps and changes in trace data patterns) to the information about special school events (e.g., "room 7 visited the zoo today"), the authors were able to successfully identify the classes to which students belong to, illustrating how such data could be used to breach data privacy. Such insights highlight how challenging it is to preserve data privacy while, at the same time, supporting highly valuable data sharing and collaboration.

Finally, the sixth and final paper in this special section is the practitioner report by Pelanek (2021) that examines schoolbased learning analytics from a unique angle of learning system designers. The author provides an overview and inventory of different data visualization approaches for common types of learning data, highlighting the benefits and challenges of the different techniques. Pelanek's (2021) study also provides an overview of different challenges when designing analytics 
systems, which include dealing with bias, contract cheating and the temporal nature of learning analytics data. We hope that this contribution provides a valuable inventory for analytics system designers faced with similar challenges.

\section{Key Takeaways from this Special Section}

One of the prominent themes in this special section has been the focus on supporting teacher decision making. The study by van Leeuwen et al. (2021), as well as studies by Krumm et al. (2021) and Cloude et al. (2021), explicitly mention support for the teachers' decision-making process as one of the aims of their studies. This is an important trend, as most of the existing educational data is used for systems-level decision-making, such as evaluating school performance and funds allocation.

Another important aspect of the included studies is that they encompass a wide range of learning scenarios and pedagogical approaches. Yacobson et al. (2021) focuses on learning with intelligent tutoring systems (ITS), van Leeuwen et al. (2021) on collaborative learning, Rodríguez-Triana et al. (2021) on IBL, and Cloude et al. (2021) on game-based problemsolving. We also see a wide range of data being utilized within school-based learning analytics systems. These include ITS data, utilized by Yacobson et al. (2021) and van Leeuwen et al. (2021), trace and performance data by Krumm et al. (2021), as well as multimodal data by Cloude et al. (2021). This shows that analytics have strong potential for supporting a wide range of learning contexts, which is important from a broader perspective of LA adoption within schools.

Another aspect that has been repeatedly discussed in this special section is the role of data interoperability standards and ways to support data integration and sharing across multiple systems. Both Yacobson et al. (2021) and Krumm et al. (2021) studies utilized xAPI standard in their LA implementation, while the study by Rodríguez-Triana et al. (2021) recommends as one of the guidelines for supporting IBL using LA - to pay special attention to data sharing standards and tool integration. A similar voice has been raised by Krumm et al. (2021), who also pointed to the challenge of semantic and conceptual mapping of data arising from different learning scenarios and contexts.

While technical aspects such as data interoperability are crucial, it is important to note that several studies emphasized the human factor in learning analytics development. For instance, both van Leeuwen et al. (2021) and Rodríguez-Triana et al. (2021) emphasize the need for (co-)designing LA systems in collaboration with teachers. Rodríguez-Triana et al. (2021) also go one step further by specifically listing teacher involvement and support for diverse needs as one of the design guidelines for supporting IBL through LA. A similar point has been raised by Krumm et al. (2021), who noted the critical importance of understanding the context in which the data is collected and the importance of non-technical activities to support collaboration and educational data sharing. This is also seen by the adoption of design-based research (DBR) by both Rodríguez-Triana et al. (2021) and Krumm et al. (2021) in their studies. Several studies also highlighted the implications for the professional development of teachers (van Leeuwen et al., 2021) and LA practitioners (Yacobson et al., 2021), as well as the importance of policy (Yacobson et al., 2021) for driving ethical LA adoption.

Finally, we also see a strong emphasis on theory-driven research and development within the LA field, drawing from a wide range of pedagogical, sociotechnical, and psychometric models. This includes the metacognitive model of reflection by McAlpine et al. (1999) utilized in the study by Cloude et al. (2021), the theory of inquiry-based learning adopted by RodríguezTriana et al. (2021), Unified Theory of Acceptance and Use of Technology (UTAUT; Venkatesh et al., 2003), and itemresponse theory model by Pelanek (2021). While these models serve a wide range of purposes, theoretically grounding the LA research and practice is paramount to enable dialogue and collaboration with other fields and build upon a vast amount of research in education and related domains.

\section{Conclusion}

Over the last decade, learning analytics have received considerable attention in non-formal and formal learning contexts due to their potential for monitoring, supporting, assessing, and managing student learning (see, for example, Few, 2013; Trezise et al., 2017) and for facilitating educational leaders' and instructors' work (Choi et al., 2018; Gutiérrez et al., 2020). However, the focus of research has so far been drawn to university contexts. This special section aims to shed more light on learning analytics in pre-university contexts such as primary and secondary schools. Here learning analytics might come in the shape of dashboards for facilitating teacher decision making (see van Leeuwen et al., 2021), supporting inquiry-based learning (see Rodríguez-Triana et al., 2021), or supporting self-reflection in educational games (see Cloude et al., 2021). These and similar forms of learning analytics are growing in numbers, specifically considering the aftermath of the COVID-19 pandemic and how it turned the spotlight onto the value of online learning.

We are aware that this special section and similar contributions only display a starting point for understanding the adoption of learning analytics in school environments. As mentioned above, young students' data privacy and parents' concerns are only two factors that need to be carefully considered when planning to implement the learning analytics tool at the school level. 
Other school-related factors that are not completely understood yet relate to the non-technical aspects of adoption, such as the integration of different stakeholder perspectives, different needs, specifically designed professional development and potentially ways to deal with end-user reluctance (due to time limitations and student schedules) or low understanding of the functionality and use of learning analytics. While the lessons we have learned from the university context are undoubtedly valuable for conceptualizing the adoption of learning analytics at the school level, they are just a starting point since they do not yet completely address the particularities of the school context. We hope to see an increasing number of studies addressing some of these issues, leading a path to broader and more effective adoption of learning analytics within school contexts.

\section{Declaration of Conflicting Interest}

The authors declared no potential conflicts of interest with respect to the research, authorship, and publication of this article.

\section{Acknowledgement}

The guest editors would like to thank the journal managers and the staff of the Journal of Learning Analytics for their support in all practicalities. The guest editors would also like to thank the authors and reviewers, without whom this special section would never have come to pass.

\section{References}

Bienkowski, M. A., Feng, M., \& Means, B. (2012). Enhancing teaching and learning through educational data mining and learning analytics: An issue brief. U.S. Department of Education. Retrieved from https://tech.ed.gov/wpcontent/uploads/2014/03/edm-la-brief.pdf

Choi, S. P., Lam, S. S., Li, K. C., \& Wong, B. T. (2018). Learning analytics at low cost: At-risk student prediction with clicker data and systematic proactive interventions. Journal of Educational Technology \& Society, 21(2), 273-290. https://www.j-ets.net/collection/published-issues/21_2

Cloude, E., Carpenter, D., Dever, D. A., Azevedo, R., \& Lester, J. (2021). Game-based learning analytics for supporting adolescents' reflection. Journal of Learning Analytics, 8(2), 51-72. https://doi.org/10.18608/jla.2021.7371

Few, S. (2013). Information dashboard design: Displaying data for at-a-glance monitoring (2nd Ed.). El Dorado Hills, CA: Analytics Press.

Freeman, A., Adams Becker, S., Cummins, M., Davis, A., \& Hall Giesinger, C. (2017). NMC/CoSN Horizon Report: 2017 K-12 edition. The New Media Consortium. Retrieved from https://library.educause.edu/ /media/files/library/2017/11/2017hrk12EN.pdf

Gonski, D., Arcus, T., Boston, K., Gould, V., Johnson, W., O’Brien, L., Perry, L.-A., \& Roberts, M. (2018). Through growth to achievement: Report of the review to achieve educational excellence in Australian schools. Department of Education and Training. Retrieved from https://www.dese.gov.au/quality-schools-package/resources/through-growthachievement-report-review-achieve-educational-excellence-australian-schools

Gutiérrez, F., Seipp, K., Ochoa, X., Chiluiza, K., De Laet, T., \& Verbert, K. (2020). LADA: A learning analytics dashboard for academic advising. Computers in Human Behavior, 107, 105826. https://doi.org/10.1016/j.chb.2018.12.004

Gunawardena, A. (2017). Brief survey of analytics in K-12 and higher education. International Journal on Innovations in Online Education, 1(1). https://doi.org/10.1615/IntJInnovOnlineEdu.v1.i1.80

Horn, M. B., \& Staker, H. (2011). The rise of $K-12$ blended learning. Innosight Institute. Retrieved from https://www.christenseninstitute.org/wp-content/uploads/2013/04/The-rise-of-K-12-blended-learning.emergingmodels.pdf

Krumm, A. E., Boyce, J., \& Everson, H. T. (2021). A collaborative approach to sharing learner event data. Journal of Learning Analytics, 8(2), 73-82. https://doi.org/10.18608/jla.2021.7375

Li, K. C., Lam, H. K., \& Lam, S. S. (2015). A review of learning analytics in educational research. In J. Lam, K. K. Ng, S. K. S. Cheung, T. L. Wong, K. C. Li, \& F. L. Wang (Eds.), Technology in education: Technology-mediated proactive learning (pp. 173-184). Berlin, Germany: Springer. https://doi.org/10.1007/978-3-662-48978-9 17

Lodge, J. M., Horvath, J. C., \& Corrin, L. (2018). Learning analytics in the classroom: Translating learning analytics for teachers. Abingdon-on-Thames, UK: Routledge.

McAlpine, L., Weston, C., Beauchamp, C., Wiseman, C., \& Beauchamp, J. (1999). Building a metacognitive model of reflection. Higher Education, 37(2), 105-131. https://doi.org/10.1023/A:1003548425626

McRae, P. (2014). Rebirth of the teaching machine through the seduction of data analytics: This time it's personal. Revista Intercambio, 6, 28-32. http://revistaintercambio.org/ojsclon/index.php/INTERCAMBIO/article/view/25 
Ochoa, X. (2017). Multimodal learning analytics. In C. Lang, G. Siemens, A. F. Wise, \& D. Gaševic (Eds.), The handbook of learning analytics (1st ed., pp. 129-141). Beaumont, AB: Society for Learning Analytics Research (SoLAR). http://solaresearch.org/hla-17/hla17-chapter1

Pelanek, R. (2021). Analyzing and visualizing learning data: A system developer's perspective. Journal of Learning Analytics, 8(2), 93-104. https://doi.org/10.18608/jla.2021.7345

Roberts-Mahoney, H., Means, A. J., \& Garrison, M. J. (2016). Netflixing human capital development: Personalized learning technology and the corporatization of K-12 education. Journal of Education Policy, 31(4), 405-420. https://doi.org/10.1080/02680939.2015.1132774

Rodríguez-Triana, M. J., Prieto, L. P., Dimitriadis, Y., de Jong, T., \& Gillet, D. (2021). ADA for IBL: Lessons learned in aligning learning design and analytics for inquiry-based learning orchestration. Journal of Learning Analytics, 8(2), 22-50. https://doi.org/10.18608/jla.2021.7357

Sancho, M.-R., Cañabate, A., \& Sabate, F. (2015). Contextualizing learning analytics for secondary schools at micro level. Proceedings of the 2015 International Conference on Interactive Collaborative and Blended Learning (ICBL 2015), 9-11 December 2015, Mexico City, Mexico (pp. 70-75) Washington, DC: IEEE Computer Society. https://doi.org/10.1109/ICBL.2015.7387638

Selwyn, N., \& Facer, K. (2013). The politics of education and technology: Conflicts, controversies, and connections. New York, NY: Springer. https://doi.org/10.1057/9781137031983

Singer, N. (2014). InBloom student data repository to close. The New York Times Bits Blog. Retrieved from http://bits.blogs.nytimes.com/2014/04/21/inbloom-student-data-repository-to-close/

Trezise, K., de Barba, P. G., Jennens, D., Zarebski, A., Russo, R., \& Kennedy, G. (2017). A learning analytics view of students' use of self-regulation strategies for essay writing. In H. Partridge, K. Davis, \& J. Thomas (Eds.), Me, Us, IT! Proceedings of the $34^{\text {th }}$ Annual Conference of the Australasian Society for Computers in Learning in Tertiary Education (ASCILITE 2017), 4-6 December 2017, Toowoomba, Queensland, Australia (pp. 411-421). Australasian Society for Computers in Learning in Tertiary Education. https://2017conference.ascilite.org/wpcontent/uploads/2017/11/ASCILITE-2017-Proceeding.pdf

van Leeuwen, A., Knoop-van Campen, C. A. N., Molenaar, I., \& Rummel, N. (2021). How teacher characteristics relate to how teachers use dashboards. Journal of Learning Analytics, 8(2), 6-21. https://doi.org/10.18608/jla.2021.7325

Venkatesh, V., Morris, M. G., Davis, G. B., \& Davis, F. D. (2003). User acceptance of information technology: Toward a unified view. MIS Quarterly, 27(3), 425-478. https://misq.org/user-acceptance-of-information-technology-toward-aunified-view.html?SID=tdk2f2ove4s5g7q1h8cfmnhoh5

Voogt, J., Knezek, G., Christensen, R., \& Lai, K.-W. (2018). Developing an understanding of the impact of digital technologies on teaching and learning in an ever-changing landscape. In J. Voogt, G. Knezek, R. Christensen, \& K.W. Lai (Eds.), Second handbook of information technology in primary and secondary education (pp. 3-12). Springer International Publishing. https://doi.org/10.1007/978-3-319-71054-9 113

Yacobson, E., Fuhrman, O., Hershkovitz, S., \& Alexandron, G. (2021). De-identification is insufficient to protect student privacy, or - What can a field trip reveal? Journal of Learning Analytics, 8(2), 83-92.

https://doi.org/10.18608/jla.2021.7353 